\title{
TWO HIERARCHIES IN SCIENCE: THE FREE FLOW OF IDEAS AND THE ACADEMY
}

\author{
ADRIAN BEJAN \\ J. A. Jones Distinguished Professor of Mechanical Engineering, Duke University, Durham, North Carolina, USA.
}

\begin{abstract}
Here I show that the pattern of generation of science is in disaccord with the pattern of admission to the academy. The contrast between the two patterns is illustrated with two rankings: the most highly cited authors in all US engineering and the members of the US National Academy of Engineering. Only $2.7 \%$ of the academy members are highly cited. This discrepancy raises the question of how the academicians have succeeded in this mode of self-organization. The answer is evident when we examine two drawings: (1) the numbers of highly cited authors versus the ranks of their institutions, and (2) the numbers of academy members versus the ranks of their institutions. Drawing (1) is a natural (Zipf) distribution, which is virtually the same as the hierarchy and scaling of all freely morphing flow structures in nature (e.g. city sizes on the landscape, tree sizes in the forest, and river sizes in the basins). Drawing (2) fails the natural (Zipf) test, and reveals that the flow to the academy is not free, that is, not for everybody.

Keywords: constructal law, highly cited, national academy, mafias, dark networks, university rankings, Zipf distribution.
\end{abstract}

Every professor ... one day discovers to his great surprise that the elements of his teaching which stay with his students are not the things which were 'in the program' but those other things he has communicated unknowingly to his best students.

Jaurès said it well: One does not teach what one knows, but what one is.

The computer knows many things, it can even know everything; but it is not. It is incapable of forming minds since it has no ends to offer them. But it is quite capable of reducing minds to an official conformity.

Denis De Rougemont, Information is not knowledge, 1981.

\section{THE NATURAL DESIGN OF THE FLOWING LANDSCAPE}

The flows of nature evolve in time such that they flow more and more easily, for greater access. They attain this ever improving quality through the generation of design, that is, by acquiring configuration. Existing designs (literally, drawings) are replaced by new designs that flow more easily. This natural phenomenon is covered by the constructal law: 'For a finite-size flow system to persist in time (to live), its configuration must change such that it provides easier and easier access to its currents' [1]. In this mental viewing, we fit all the evolutionary scenarios of biology, the emergence of river basins and climate, and the evolution of technologies toward greater efficiency [2-7].

The flows that connect us as a society exhibit the same natural tendency to generate configurations $[1,8]$. Commerce and knowledge (science, education, news) flow in one direction: from those who have it to those who seek it. When both ends of each such river basin have it and know it, the flow stops. What is not news does not travel.

Age matters in evolutionary design, and it is good for performance. The river basin positions its channels better and better, and the channels stay in place. The channels have hierarchy: a few large channels flow in harmony with the many small channels. A sudden downpour is served well by the 'memory' built into the old river beds.

(C) 2009 WIT Press, www.witpress.com

ISSN: 1755-7437 (paper format), ISSN: 1755-7445 (online), http://journals.witpress.com

DOI: 10.2495/DNE-V4-N4-386-394 
From the mental viewing provided by the constructal law, the hierarchies that are visible in all the flow systems that cover the globe can finally be deduced. These architectures form a multi-scale weave of point-area and area-point tree flows, all superimposed, all sustaining everything that flows (i.e. everything that lives) on earth. One example is the hierarchy of channel sizes and numbers in all the river basins that have been catalogued. From the constructal law, we deduced that the number of tributaries that feed a larger channel should be 4 [9]. This prediction is in very good agreement with Horton's empirical correlation of river numbers, which states that the observed number of tributaries falls in the range between 3 and 5 [10].

Another example of constructal hierarchy is the distribution of city sizes and numbers (of cities of the same size) on large areas such as a continent (Fig. 1) [11]. The distribution is linear when plotted $\log -\log$. This line with slope in the range between $-1 / 2$ and -1 is known as a Zipf distribution, and it is found empirically in virtually all the natural flow systems that connect discrete points with finite areas or volumes. The descending line in Fig. 1 is deduced by recognizing the flow access between two populations that live on each area construct (small and large) that covers the landscape. This is suggested by the inset in the upper-right corner of the figure. On every area construct (white), there are two populations that exchange flows: those who live on the area and those who live in a settlement (village, town, city), which is shown as a black dot. The constructal law also predicts that the straight line must shift upward in time while remaining parallel to itself because technology improves, and those who live on the area can achieve flow equilibria with larger and larger numbers of people living in the settlement. This too is in agreement with the history of the size-rank distribution over the past four centuries (Fig. 1).

Another example of natural distribution anticipated with the constructal law is the ranking of tree sizes and numbers in forests (Fig. 2) [12]. The descending bands of size versus rank data were deduced by arranging tree canopies of many sizes on the forest floor such that the entire floor facilitates the flow of water, from the ground to the blowing wind. Two examples of such arrangements (triangular and square) are shown in the upper-right corner. The slope and intercept of the size-rank line is insensitive to the type of arrangement. Important is how the multi-scale canopies fill the forest floor area such that the water flow rate from the whole area is greater. From this

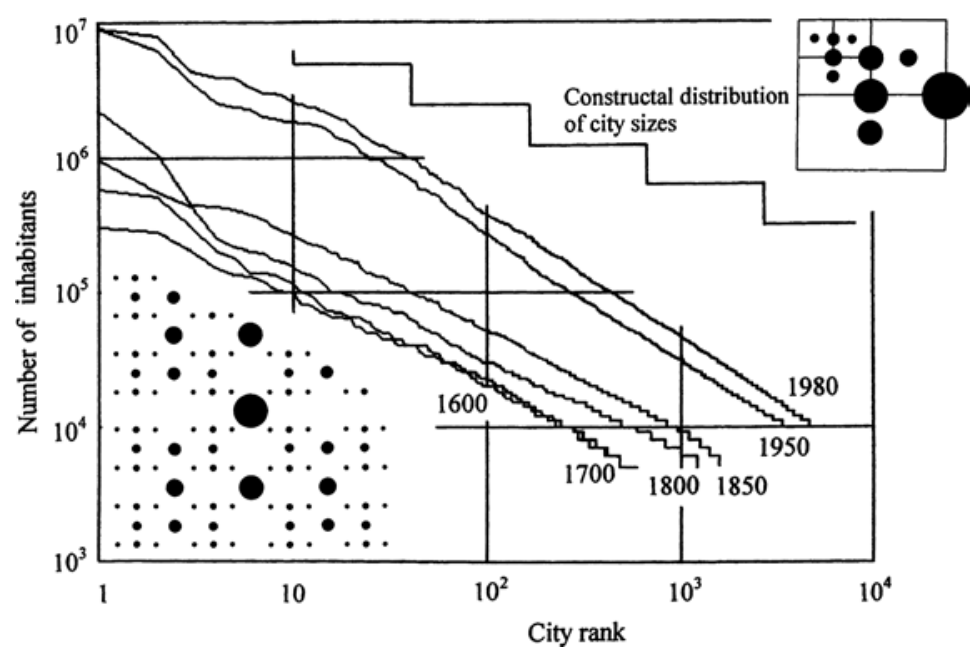

Figure 1: City sizes versus city rank in Europe during 1600-1980, and the Zipf distribution predicted with the constructal law [11]. 


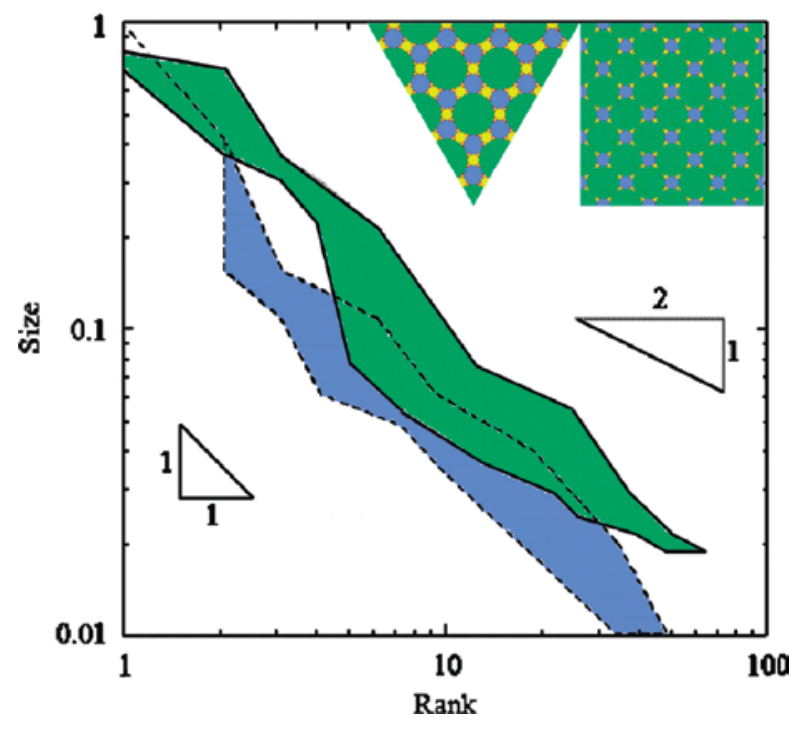

Figure 2: Distribution of tree canopy sizes versus rank in the constructal design of the forest floor [12]. The Zipf distribution is insensitive to the pattern (e.g. triangular versus square) in which the multi-scale tree canopies are arranged on the forest floor.

holistic view of design generation come the (seemingly random) multiple scales of trees in the forest, and the Zipf-type alignment of the size versus rank data.

\section{THE UNIVERSITY HIERARCHY}

What the constructal law predicted for multi-scale river basins, demography, and forests also applies to the design of societal flow. Science and education flow through a natural tissue of universities, each university being connected to the entire globe. The older universities have dug the first channels, which are now some of the largest channels that irrigate the student landscape. 'Largest' does not mean largest number of bodies moving in and out of classrooms. Largest are the streams of the most creative, i.e. the channels that attract the individuals who generate new ideas, and who develop disciples who produce and carry new ideas farther on the globe and into the future. The swelling student population is served well by the 'memory' built into the education flow architecture.

From this theoretical view followed the prediction that the hierarchy of universities should not change in significant ways [13]. This hierarchy is as permanent as the hierarchy of channels in a river basin. It is natural because it is demanded by the entire flow system (the globe), in which huge numbers of individuals want the same thing (knowledge).

The natural genesis of the hierarchy of universities is supported by the fact that the universities have essentially the same hierarchy as the ranked individuals who generate the ideas for which the universities are famous. The highly cited authors [14] have a natural hierarchy because their hierarchy is the result of the efforts and choices of very large numbers of researchers who cite the work of an idea generator and do not talk to each other before deciding to cite their sources [15]. The hierarchy of the most cited authors is an indicator of the nodes and areas (the elemental territories) of the flow of ideas.

The highly-cited hierarchy is shown in the lower part of Fig. 3, where the nearly straight band (pink) represents the ranking of universities according to the number of authors that each university 


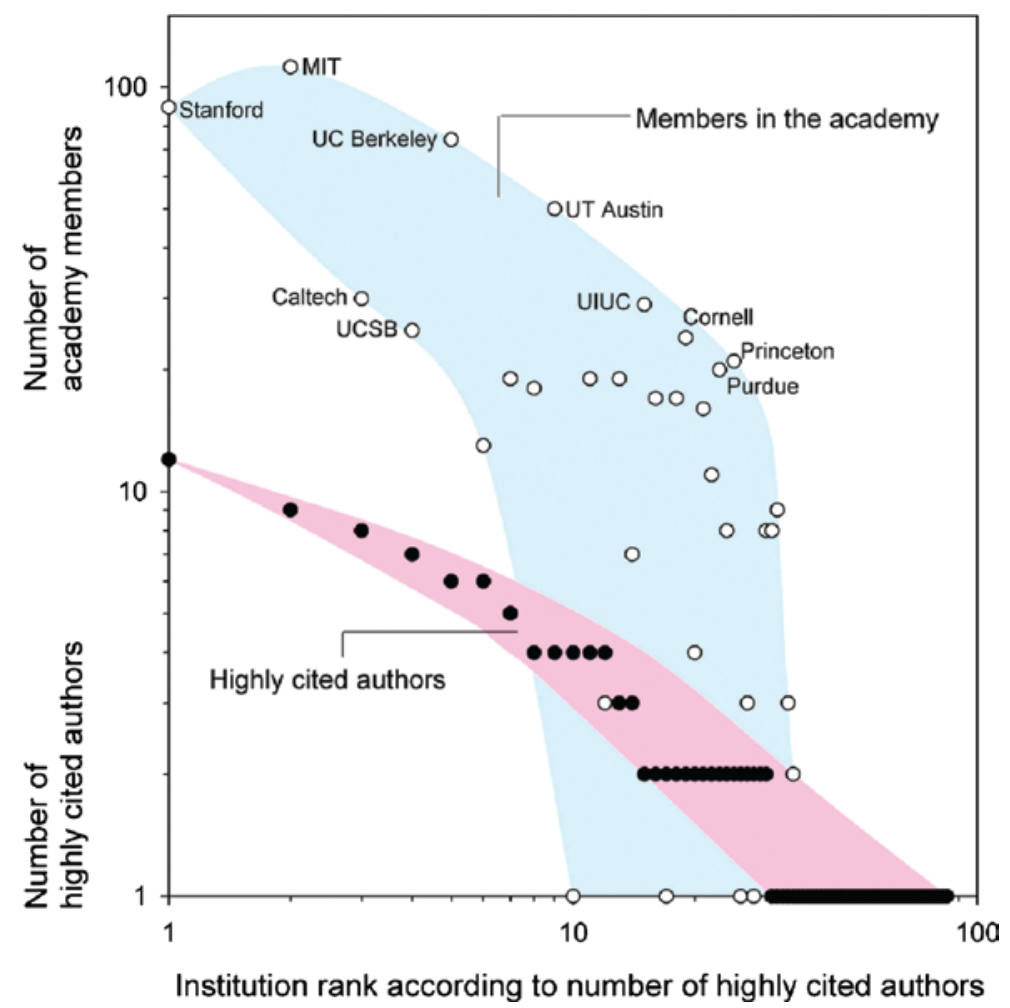

Figure 3: The ranking of institutions according to their numbers of highly cited authors (bottom). The total number of academy members of the institutions ranked according to their numbers of highly cited authors (data from Table 1) (top).

has on the highly-cited list. We discuss Fig. 3 in greater detail next. Important to note is that this band of data is nearly straight and with a slope similar to what we see in Figs 1 and 2. In conclusion, the highly cited constitute a natural hierarchy.

\section{THE DARK NETWORKS}

All the flow structures are ever improving, but some are hidden from view. In social dynamics, the hidden constitute a field of study called dark networks and mafias [16-23]. These are channels where participation is based on personal connections, on whom you know and who needs you for the safety and perpetuation of the dark network.

Here is one example that juxtaposes the clarity of the flow of ideas (Fig. 3, lower band) with the opacity of dark networks that permeate the same flow space. I picked this example from engineering, because this is my field and I know it best. I am sure that colleagues from other fields can construct analogous examples by examining their own patterns of idea production and access to the academy. Furthermore, the numbers fluctuate slightly from year to year, but the two patterns that emerge (and are discussed next) are so dissimilar that such fluctuations do not matter. 
In February 2009, the list of highly cited authors in 'Engineering' (all disciplines, all countries, living, and deceased) contained 253 names worldwide [14]. The membership in the National Academy of Engineering (US alone) contained 2440 names [24]. The 1:10 ratio between the two lists means that most of the members of the academy are not highly cited.

The contrast is even sharper. I placed this comparison on a common basis by removing from the 253 highly-cited the 80 names of researchers who work in countries other than the US. I also removed the two names of highly cited authors whom I know to be deceased (the academy deletes immediately the names of its deceased members). After these subtractions, which are conservative, the highly cited list shrank to 171 names. From the list of academicians I removed the 197 who work in foreign institutions, and kept the remaining 2243. The resulting comparison is between 171 highly cited and 2243 academicians, which form the ratio 1:13. Furthermore, only one-third of the highly cited authors (namely, 60) are also in the academy, and they represent only $2.7 \%$ of the 2243 members of the academy.

If not highly cited, then exactly what are the academicians? There is no answer to this. The reason is that unlike the highly cited list, which is clean and naked on the table, the path to the national academy is not. The creative author cannot put himself in the academy in the way that his ideas put him on the highly cited list. Consider this: the large numbers of researchers who vote for one highly cited author every day by using and citing ideas in the literature are nobodies in the eyes of the academy. They are not inside the academy, they cannot nominate, and they cannot vote for an idea person.

Why should anybody with common sense expect the academicians to be highly cited? Because the word 'academy' means a house in which knowledge is generated, debated, and transmitted. The first such institution was Plato's Academia (387 BC, named after its quarter in Athens, which was named after the sixth century BC mythical hero Academus). In modern times, 'academia' became synonymous with the highest peaks of idea generation and transmission. And, why not? The science debated in the Academia was geometry and mechanics, i.e. the legs of engineering science today. Written above the entrance was outhis ageometritos isito (rough translation: the person who cannot think geometrically cannot enter).

Science was the ticket for admission to the academy. The organs that publish university rankings certainly believe this because their formulas are weighted in favor of universities that have many members in the academy. These organs are mistaken, and their error is magnified by the feedback mechanism that the publication of university rankings has put in place. Each university strives to have more members in the academy, but the successful universities are the ones that already have the largest number of members (these universities are the insiders).

\section{THE ACADEMY VERSUS THE HIGHLY CITED}

Table 1 shows the ranking of institutions according to the number of researchers that each institution has on the highly cited list. Mentioned already is that when plotted $\log -\log$ as the number of highly cited names belonging to one institution versus the rank of the institution (as in the lower part of Fig. 3), the data form a Zipf line. This alignment is found not only in river basins, demography, and forests, but also in all the natural multi-scale systems that must flow while being confined to finite areas and finite volumes, for example, the use of words in human and computer languages, operating systems calls, colors in images, and many compression approaches. Because the Zipf distributions of Figs 1 and 2 agree with the organization observed in nature, the distribution shown in the lower part of Fig. 3 confirms the notion that science is a flow system with a natural multi-scale architecture covering the globe and morphing incessantly so that it flows better and better for everybody. 
Table 1: The top 83 institutions ranked according to their numbers of highly cited authors.

\begin{tabular}{|c|c|c|c|c|c|}
\hline Rank & Institution & $\begin{array}{c}\text { Total } \\
\text { number of } \\
\text { academy } \\
\text { members }\end{array}$ & $\begin{array}{l}\text { Number of } \\
\text { highly cited } \\
\text { authors }\end{array}$ & $\begin{array}{l}\text { Number of } \\
\text { academy members } \\
\text { who are also } \\
\text { highly cited }\end{array}$ & $\begin{array}{l}\text { Number of } \\
\text { highly cited } \\
\text { not in the } \\
\text { academy }\end{array}$ \\
\hline 1 & Stanford & 89 & 12 & 5 & 7 \\
\hline 2 & MIT & 112 & 9 & 3 & 6 \\
\hline 3 & Caltech & 30 & 8 & 4 & 4 \\
\hline 4 & $\begin{array}{l}\text { University of California, } \\
\text { Santa Barbara }\end{array}$ & 25 & 7 & 7 & 0 \\
\hline 5 & $\begin{array}{l}\text { University of California, } \\
\text { Berkeley }\end{array}$ & 74 & 6 & 4 & 2 \\
\hline 6 & Sandia & 13 & 6 & 1 & 5 \\
\hline 7 & Northwestern & 19 & 5 & 4 & 1 \\
\hline 8 & $\begin{array}{l}\text { University of California, } \\
\text { San Diego }\end{array}$ & 18 & 4 & 3 & 1 \\
\hline 9 & University of Texas, Austin & 50 & 4 & 3 & 1 \\
\hline 10 & Michigan & 1 & 4 & 3 & 1 \\
\hline 11 & $\begin{array}{l}\text { University of California, } \\
\text { Los Angeles }\end{array}$ & 19 & 4 & 3 & 1 \\
\hline 12 & Lucent & 3 & 4 & 2 & 2 \\
\hline 13 & Wisconsin & 19 & 3 & 0 & 3 \\
\hline 14 & Florida & 7 & 3 & 0 & 3 \\
\hline 15 & $\begin{array}{l}\text { University of Illinois, } \\
\text { Urbana-Champaign }\end{array}$ & 29 & 2 & 2 & 0 \\
\hline 16 & Harvard & 17 & 2 & 2 & 0 \\
\hline 17 & City College of New York & 1 & 2 & 2 & 0 \\
\hline 18 & Minnesota & 17 & 2 & 2 & 0 \\
\hline 19 & Cornell & 24 & 2 & 1 & 1 \\
\hline 20 & Brown & 4 & 2 & 1 & 1 \\
\hline 21 & $\begin{array}{l}\text { International Business } \\
\text { Machines }\end{array}$ & 16 & 2 & 1 & 1 \\
\hline 22 & Virginia & 11 & 2 & 1 & 1 \\
\hline 23 & Purdue & 20 & 2 & 1 & 1 \\
\hline 24 & University of California, Irvine & 8 & 2 & 1 & 1 \\
\hline 25 & Princeton & 21 & 2 & 1 & 1 \\
\hline 26 & $\begin{array}{l}\text { University of California, } \\
\text { Riverside }\end{array}$ & 1 & 2 & 0 & 2 \\
\hline 27 & Livermore & 3 & 2 & 0 & 2 \\
\hline 28 & $\begin{array}{l}\text { United States Geological } \\
\text { Survey }\end{array}$ & 1 & 2 & 0 & 2 \\
\hline 29 & Old Dominion & 0 & 2 & 0 & 2 \\
\hline 30 & Rutgers & 8 & 2 & 0 & 2 \\
\hline 31 & North Carolina State & 8 & 1 & 1 & 0 \\
\hline 32 & Arizona & 9 & 1 & 1 & 0 \\
\hline 33 & Notre Dame & 0 & 1 & 1 & 0 \\
\hline 34 & Honeywell & 3 & 1 & 1 & 0 \\
\hline & Syracuse & 2 & 1 & 1 & 0 \\
\hline \multicolumn{2}{|c|}{$36-83 \ldots$} & $\ldots$ & 1 & 0 & 1 \\
\hline
\end{tabular}




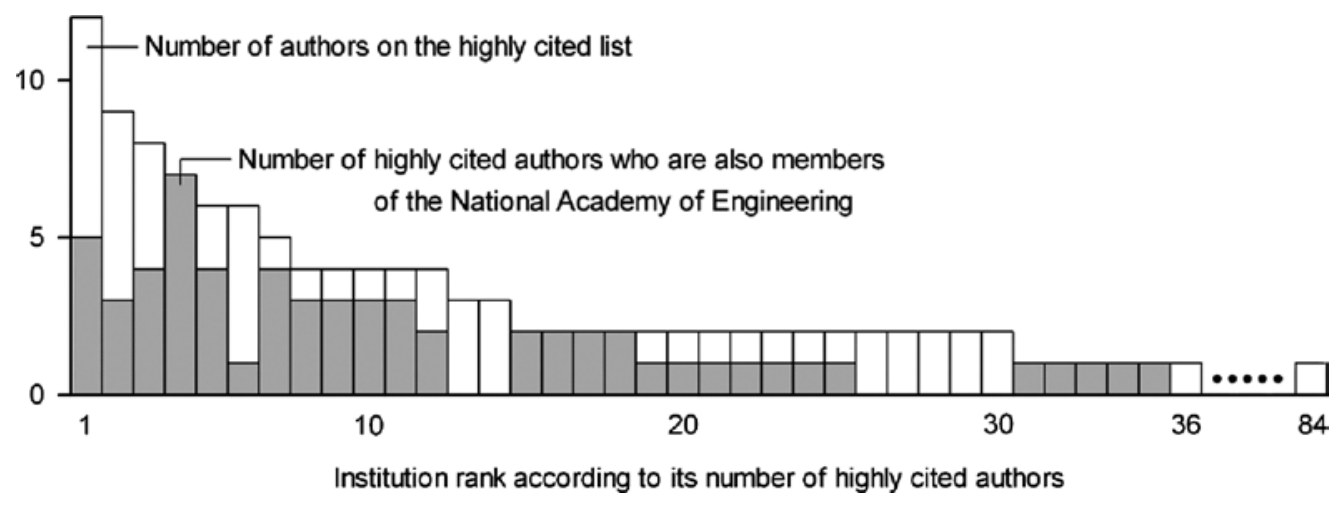

Figure 4: The ranking of institutions according to their numbers of highly cited authors, also showing the number of highly cited authors who are also members of the National Academy of Engineering.

The ranking of institutions according to their highly cited authors who are also academy members (Table 1, third column) tells an entirely different story (Fig. 3, upper part). There is no parallelism, that is, no proportionality between the numbers of highly cited and the numbers of academicians who are highly cited. The latter do not align themselves as a Zipf distribution, parallel to the Zipf distribution seen in the lower part of Fig. 3.

The discrepancy between the second and third columns of numbers in Table 1 is illustrated further in Fig. 4. Each bar represents the number of highly cited authors of an institution. The shaded portion of each bar indicates the number of those who are also members of the academy. The dissonance between the two sets of bars is striking, and it invites speculations as to why the academy admits its few highly cited researchers only from certain origins (e.g. from UC Santa Barbara and Northwestern) and does not consider the rest.

Such speculations are not science. The science is the natural phenomenon of dissonance between the two distributions, which along with the 1:13 ratio noted earlier identifies the academy as a flow network the channels visible to and used by only those who are on the inside. Who is on the inside is put on display in the upper part of Fig. 3. The total number of academy members of each highly cited institution is listed in the first column of Table 1 . When plotting these numbers against the institution rank, we see a sharp cut-off separating a certain group of institutions from the rest. The cut-off is even more evident in Fig. 5, which used on the abscissa the ranking according to academy membership.

The names of the insiders are known to everybody, like the names of the few powerful families in a certain rural area. See the highest points in Fig. 3. Once inside the house, the family invites in the relatives, not the strangers.

\section{WHAT TO DO}

In this paper, I showed that the pattern of generation of good ideas is in disaccord with the pattern of admission to the academy. The reason is that knowledge and academy membership are two very different flow systems on the same geography. One is free to morph into a natural flow configuration, while the other is not.

The applicability of these findings is more general [16-23]. All steps of promotion, honors and peer review in the science profession, all the way to the difficulty of publishing in Nature, can be analyzed in the way that the promotion to the national academy was analyzed here. 


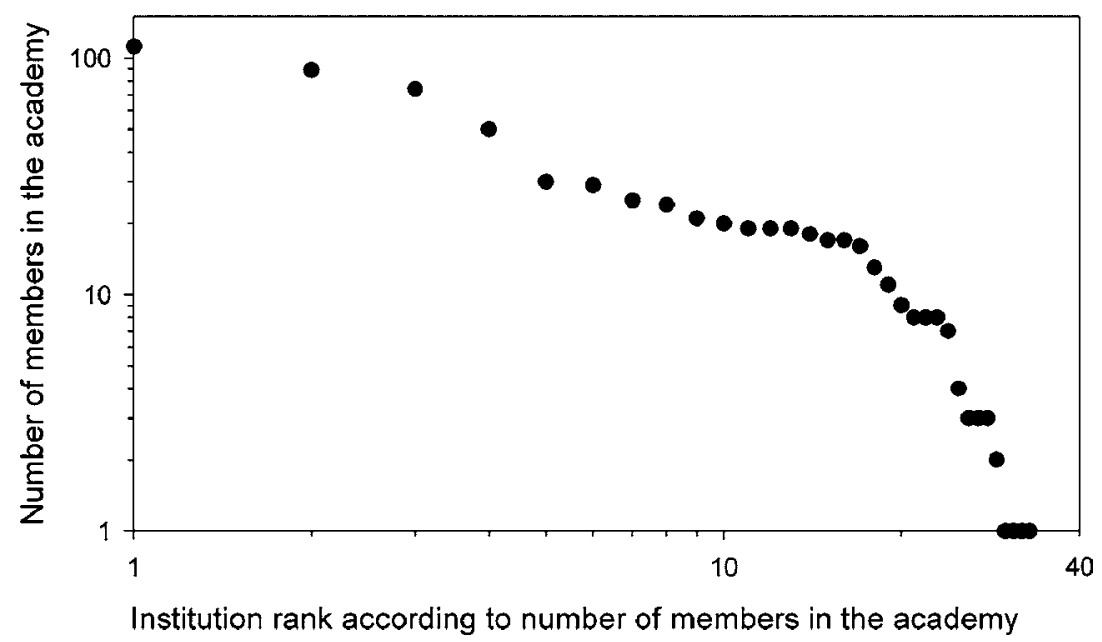

Figure 5: The total number of academy members of the top institutions ranked according to their numbers of academy members.

Here is why researchers should become aware of the self-organization phenomenon described in this paper.

Firstly, contrary to the apparently Darwinian 'publish or perish' doctrine, it takes more than good ideas, publications, and citations before one is admitted into academic clubs. It takes connections and the ability and promise to preserve the dark networks, that is, not to threaten them.

Secondly, the dissonance between the two hierarchies (highly cited versus academy) is physics. It cannot be changed by one or two individuals, because this dissonance is itself a natural pattern that results from the actions of very large numbers of individuals who pursue the same goals.

Finally, the aspiring researcher should make a choice early, and stick with it. If the researcher is creative, then the 'highly cited' is the stadium in which to play. Along that route, it is important to keep in mind what science (knowledge) is, cf. Jean Jaurès' and Denis de Rougemont's observation at the start of this article.

\section{ACKNOWLEDGEMENTS}

This research was supported by the National Science Foundation. I also acknowledge the assistance received from Professor Kuan-Min Wang of Tatung University, Taipei, Taiwan.

\section{REFERENCES}

[1] Bejan, A., Advanced Engineering Thermodynamics, 2nd edn, Wiley: New York, 1997.

[2] Bejan, A., Shape and Structure, from Engineering to Nature, Cambridge University Press: Cambridge, UK, 2000.

[3] Bejan, A. \& Lorente, S., Constructal theory of generation of configuration in nature and engineering. J. Appl. Phys., 100, p. 041301, 2006. doi:10.1063/1.2221896

[4] Reis, A.H., Constructal theory: from engineering to physics, and how flow systems develop shape and structure. Appl. Mech. Rev., 59, pp. 269-282, 2006. doi:10.1115/1.2204075

[5] Poirier, H., A theory explains the intelligence of nature. Science \& Vie, 1034, pp. 44-63, 2003.

[6] Reis, A.H., Constructal view of scaling laws of river basins. Geomorphology, 78, pp. 201-206, 2006. doi:10.1016/j.geomorph.2006.01.015 
[7] Miguel, A.F., Constructal pattern formation in stony corals, bacterial colonies and plant roots under different hydrodynamics conditions. J. Theor. Biol., 242, pp. 954-961, 2006. doi:10.1016/j.jtbi.2006.05.010

[8] Bejan, A. \& Merkx, G.W. (eds), Constructal Theory of Social Dynamics, Springer: New York, 2007.

[9] Bejan, A., Lorente, S., Miguel, A.F. \& Reis, A.H., Constructal theory of distribution of river sizes (Section 13.5 in A. Bejan). Advanced Engineering Thermodynamics, 3rd edn, Wiley: Hoboken, 2006.

[10] Rosa, R.N., River basins: geomorphology and dynamics. Bejan's Constructal Theory of Shape and Structure, eds R.N. Rosa, A.H. Reis \& A.F. Miguel, Évora Geophysics Center, University of Évora: Portugal, 2004.

[11] Bejan, A., Lorente, S., Miguel, A.F. \& Reis, A.H., Constructal theory of distribution of city sizes (Section 13.4 in A. Bejan). Advanced Engineering Thermodynamics, 3rd edn, Wiley: Hoboken, 2006.

[12] Bejan, A., Lorente, S. \& Lee, J., Unifying constructal theory of tree roots, canopies and forests. J. Theor. Biol., 254(3), pp. 529-540, 2008. doi:10.1016/j.jtbi.2008.06.026

[13] Bejan, A., Why university rankings do not change: education as a natural hierarchical flow architecture. Int. J. Des. Nat., 2, pp. 319-327, 2007. doi:10.2495/JDN-V2-N4-319-327

[14] ISIHighlyCited.com, www.isihighlycited.com.

[15] Antunes, A., Encouraging good science on the web. Physics Today, pp. 41-42, 2009. doi: $10.1063 / 1.3212692$

[16] Scheff, T.J., Academic gangs. Crime, Law \& Social Change, 23, pp. 157-162, 1995. doi:10.1007/BF01298529

[17] Soler, J.J., Moller, A.P. \& Soler, M., Mafia behavior and the evolution of facultative virulence. J. Theor. Biol., 191, pp. 267-277, 1998. doi:10.1006/jtbi.1997.0599

[18] Clark, B.R., The many pathways of academic coordination. Higher Education, 9, pp. 251-267, 1979. doi:10.1007/BF00137211

[19] Chaput de Saintonage, M. \& Pavlovic, A., Cheating. Medical Education, 38, pp. 8-9, 2004. doi:10.1046/j.1365-2923.2004.01771.x

[20] News: Italy continues R \& D reforms. Nature Medicine, 4(9), p. 993, 1998.

[21] Xu, J. \& Chen, H., The topology of dark networks. Communications of the ACM, 51(10), pp. 58-65, 2008. doi:10.1145/1400181.1400198

[22] Bejan, A., Constructal self-organization of research: empire building versus the individual investigator. Int. J. Des. Nat. Ecodyn., 3, pp. 177-189, 2008. doi:10.2495/DNE-V3-N3-177-189

[23] Mazur, S., Margulis: peer review or "cycle of submission", Scoop, 5 January 2010, http://www. scoop.co.nz/stories/HL1001/S00010.htm

[24] http://www.nae.edu/nae/naehome.nsf. 